\title{
SURGICAL SITE INFECTIONS, AN EXPERIENCE AT TERTIARY CARE HOSPITAL
}

Lailama Shaha, Shahzada Amir Ahmed Babera, Shabir Ahmed Lehrib, Ibrahim Balochc, Muhammad Iqbal Khand, Riffat Arbabe

assistant Professor, Department of Surgery, Bolan Medical College Quetta.

bProfessor, Department of Neurosurgery, Dean/Director Post-graduate Medical Institute Quetta.

cPostgraduate Resident, Department of Surgery, Bolan Medical Complex Hospital (BMCH).

${ }^{\mathrm{d} A s s i s t a n t ~ P r o f e s s o r, ~ D e p a r t m e n t ~ o f ~ S u r g e r y / D e p u t y ~ R e g i s t r a r ~ P o s t-G r a d u a t e ~ M e d i c a l ~ I n s t i t u t e ~ Q u e t t a . ~}$

eAssistant Professor, Department of Surgery Bolan Medical College Quetta.

\section{ABSTRACT:}

\section{BACKGROUND \& OBJECTIVE:}

Surgical site infections (SSI) are important cause of morbidity and mortality in admitted patients worldwide. The objective is to determine the incidence of surgical site infection in General Surgical ward of a tertiary care hospital.

METHODOLOGY: Analytical cross-sectional study conducted at Department of General Surgery, Bolan Medical College/ Post-Graduate Medical Institute Quetta (PGMI) for a period of one year from 1st August 2019 to 31st July 2020. Descriptive statistics were used to present socio-economics, factors related to surgery and surgical antimicrobial prophylaxis received. Chi square test was used for checking association between infections and different factors keeping $p \leq 0.05$ as significant.

RESULTS: A total of 1500 patients underwent surgery, of which 500(33.33\%) patients were operated as elective cases and $1000(66.66 \%)$ cases as emergency. Out of total 1500 patients, 600(40\%) developed Surgical Site Infection (SSI). Risk associated with higher incidence of SSI were found to be age (30-45 years) and Diabetes mellitus (uncontrolled diabetes in perioperative period). Postoperatively obesity was noted to be having significant effect with $p=0.0002$, American Society of Anesthesiologists (ASA) score having $p$-value 0.045 , hospital stay with $p<0.001$ and surgical type and previous surgical history with $\mathrm{p}<0.001$, were as duration of surgery was having $\mathrm{p}<0.001$.

CONCLUSION: Prevention of SSI requires a multipronged approach with emphasis on optimizing preoperative issues, adhering to strict protocols during the intraoperative period and addressing and optimizing metabolic and nutritional status in post-operative period.

KEYWORDS: Surgical site infection, Elective cases, Emergency cases, Wound infection.

https://doi.org/10.37723/jumdc.v12i3.536

How to cite this:

Shah L, Baber M SA, Lehri SA, Baloch I, Khan MI, Arbab R.Surgical Site Infections an Experience at Tertiary Care Hospital. Journal of University Medical \& Dental College. 2021;12(3):185-192.https:// doi.org/10.37723/jumdc.v12i3.536

This is an Open Access article distributed under the terms of the Creative Commons Attribution License (http://creativecommons.org/licenses/by/4.0), which permits unrestricted use, distribution, and reproduction in any medium provided the original work is properly cited. 


\section{INTRODUCTION:}

Healthcare-Associated Infections (HAIs) is a subject in which the great concerns of healthcare services are involved. Surgical site infections (SSI) are seen in the surgical procedures and is the most important among the topographies of $\mathrm{HAIs}^{[1]}$.Against the bacterial infections of internal organ, skin plays a key role as a barrier. Whenever a surgical wound happens, it disrupts the barrier[2]. The main cause of SSI is the bacteria present on the skin all the time and the complexities of surgical procedures ${ }^{[3]}$. According to the range from low to high clinical significance, SSI involves different inflammatory responses ${ }^{[4]}$, with surgery of abdomen being a typical example related to the increase mortality and morbidity ${ }^{[5]}$. With the worst scenario, SSI spreads into abdomen and surrounding tissues and important structures that can disrupt the entire hemostasis and this often require drainage ${ }^{[6]}$. In general surgery SSI occurs $2 \%$ to $5 \%$ in hospitals where as in ICU sitting it is very much less discussed as severe SSI leads to severe peritonitis, and as a critical public health care problem it requires particular attention ${ }^{[7]}$.

In United States, approximately 160,000 to 300,000 SSI occurs every year ${ }^{[8]}$. With the increase in SSI, patient debilitates and there is dramatical increase in health care cost. In Pakistan, the occurrence of SSI in electiveand emergency surgeries is $4.6 \%$ and $12.7 \%$ respectively ${ }^{[9]}$. Three classes of SSI are Superficial, Deep incisional SSI, and Organ/ Space SSI. The treatment of SSI is very costly especially when a lot of surgical procedures and their complexities are considered in the referral hospitals ${ }^{[10,11] .}$

Morbidity and mortality rates of secondary and tertiary conditions are high as $17-63 \%{ }^{[12]}$. Mortality rate of tertiary peritonitis is about 30 $63 \%$ and it usually occurs in the ICU setting while dealing with secondary peritonitis for $48-72 \mathrm{~h}$ [13]. Where as the chances and risks of SSI related with abdominal surgeries are $2-8 \%$ depending upon the surgery ${ }^{[14]}$.

Classification of SSI is $2 \%$ Clean, 3\% Cleancontaminated, $6 \%$ Contaminated and $7 \%$ Dirty ${ }^{[2,15]}$. Before surgery, the stratification for surveillance can identify at-risk patients. There are several risk factors that lead to SSI and makeup a surgical infection risk index.
ExamplelikeAmerican Society of Anesthesiologists (ASA) scoring, the Class of Wound, and the duration of Surgery in order to minimize the chances of SSI ${ }^{[4,16]}$. Despite of all this, operating settings such as elective and emergency have a significant role in determining the SSI [6,12].

Corresponding Author:

Dr. Muhammad Iqbal

Assistant Professor Department of Surgery

Deputy Registrar Post-Graduate Medical

Institute Quetta.

Email: miqbaljaffar@gmail.com

\section{METHODOLOGY:}

An Analytical cross-sectional study was conducted at the Department of surgery \& ICU Bolan medical complex/ Post-Graduate Medical Institute Quetta (PGMI) from 1st August 2019 to 31st July 2020. After taking approval from ethical committee. Data was collected by nonprobability convenient sampling.

Inclusion criteria: A total of 1500 patients admitted as either elective or emergency cases were included in the study. All patients with age $>5$ years were included in the study. We included all consecutive patients from any type of abdominal surgery who required ICU admission beyond $72 \mathrm{~h}$ for secondary or tertiary peritonitis after taking informed consent.

Exclusion criteria: Cases of wound infection operated elsewhere, diabetic foot and abscesses were excluded. Patients not willing to participate in study, receiving antimicrobial at time of admission or stopped receiving within 48 hours before operation and patients with initial diagnosis suggestive of infection were excluded. All patients received standard preoperative hygiene care and antibiotic prophylaxis at an anesthetic drug induction consistent with our institutional protocols for elective and emergency surgeries. Clean wound is an infection less wound in which no inflammation is present at wound and none of the genital, alimentary or urinary tracks are opened during or before surgery. Clean wounds are basically closed primarily or drained by closed drainage. If the criteria meet then the incision occurred at operation with blunt trauma must be included in this category.

JUMDC Vol. 12, Issue 3, July-September, 2021 
Cleaning of contaminated wound is basically an operative wound cleaning in which alimentary, respiratory or urinary tracts are involved under the normal and unusual contamination examples are surgeries of appendix, vaginal track, biliary track etc. Records have been accumulated by way of trained nurses (BSc) no longer operating or working at surgical wards. The data was obtained on a pretested record collection tool prepared by study group. The study group supervised the facts series method every day. Socio-demographic and other patient related factors have been obtained without delay from sufferer or affected person's scientific chart. Statistics on time of antimicrobial prophylaxis management and intra-operative doses were gathered with the aid of direct commentary and from sufferer's operation word.

The variables protected have been age in years, gender, admission date, co-morbidity, body mass index, systemic steroid use, malnutrition, immunity, date of surgery, type of surgical treatment, wound magnificence (easy or smooth-infected), time of skin incision, duration of operation and quantity of blood lost at some stage in operation.

\section{ANTIMICROBIAL PROPHYLAXIS DESCRIPTION:}

Ceftriaxone $1 \mathrm{~g}$ was given to patients. In Govt hospitals more sophisticated drugs are only used when complex infections are encountered. Concerning surgical antimicrobial prophylaxis used, route through which antimicrobials were administered, name of antimicrobials, doses, first dose administration time, time of intra-operative dose administration, time of postoperative dose given and duration of administration had been recorded. We followed the sufferers and reviewed the charts daily, throughout and after operation till the sufferers had been discharged from the healthcare facility and after discharge until 30 days.

\section{STATISTICAL ANALYSIS:}

SPSS-22 version was used for data analysis. Descriptive statistics were used to present socio- economics, factors related to surgery and surgical antimicrobial prophylaxis received. We used frequency, percentage and cross tabulation to describe patient's characteristics, operational and surgical factors. Chi square test was used for checking association between infections and different factors. Significance level was check at $\mathrm{p} \leq 0.05$.

\section{RESULTS:}

Out of 1500 patients, 856(75.06\%) were male and $644(42.93 \%)$ were female. Out of total $1500,799(53.29 \%)$ were belonging to urban and $701(46.73 \%)$ belong to rural area. Mean age of patients was $31.98 \pm 10.55$ years. 325 patients were lying in age group of 5-15 years, 549 patients were lying in age group of $16-30$ years, 398 patients were lying in age group of 31-45 years and 228 patients were lying in age group of $>45$ year. The mean Body Mass Index (BMI) was $23.72 \pm 5 \mathrm{~kg} / \mathrm{m} 2,550(36.66 \%)$ were obese with BMI $>30 \mathrm{Kg} / \mathrm{m} 2$ and $950(63.33 \%)$ were obese with BMI $\leq 30 \mathrm{~kg} / \mathrm{m} 2$. Regarding ASA scoring, 900(60\%) patients fell in ASA-II class. The Mean of total preoperative hospital stay of patients was $9.45 \pm 0.345$ as shown in Table-I.

Out of 1500 patients, 300(20\%) were of hernia procedure, $115(7.66 \%)$ were of urological surgeries, $175(11.66 \%)$ were of breast surgery, $360(24 \%)$ patients had hand and neck surgeries, $250(16.66 \%)$ had vascularprocedures, 300(20\%) had Gastrointestinal surgical procedures (tableII). After that, surgical related factor are noted. Out of 1500 patients, $1000(66.66 \%)$ patients were operated in emergency and 500(33.33\%) were in elective surgeries. $850(56.66 \%)$ were in clean wound cases and $950(63.33 \%$ ) had previous surgical history (Table-III). At the end we checked association of surgical infection with different factors. Significant association were found of postoperative side effects with obesity having <0.001, ASA score having p-value $<0.001$, hospital stay having $<0.001$ and surgical type and previous surgical history with $<0.001$, and duration of surgery with $<0.001$ (Table-IV). 
Shah L, Baber MSA, et al., SURGICAL SITE INFECTIONS AT TERTIARY CARE HOSPITAL

Table-I: Demographic features of patients.

Table-II: Surgical procedures.

\begin{tabular}{|c|c|}
\hline \multicolumn{2}{|c|}{ Obesity } \\
\hline \multicolumn{2}{|c|}{ Obacteristic (\%) } \\
\hline BMI $<30 K G / M 2$ & $950(63.33)$ \\
\hline BMI $\geq 30 K G / M 2$ & $550(36.66)$ \\
\hline ASA SCORE \\
\hline I & $450(30)$ \\
\hline III & $900(60)$ \\
\hline Preoperative Hospital stays \\
\hline$\leq 8$ DAYS & $900(60)$ \\
\hline$>8$ DAYS & $600(40)$ \\
\hline Total & $1500(100 \%)$ \\
\hline
\end{tabular}

\begin{tabular}{|c|c|}
\hline Surgical Procedures & n (\%) \\
\hline Hernia Repair & $300(20)$ \\
\hline Urological surgery & $115(7.66)$ \\
\hline Breast surgery & $175(11.66)$ \\
\hline Hand and neck surgery & $360(24)$ \\
\hline Vascular procedure & $250(16.66)$ \\
\hline Gastrointestinal surgery & $300(20)$ \\
\hline Total & $\mathbf{1 5 0 0 ( 1 0 0 \% )}$ \\
\hline
\end{tabular}

Table-III: Surgical related factors

\begin{tabular}{|c|c|}
\hline Factors & n (\%) \\
\hline \multicolumn{2}{|c|}{ Wound Class } \\
\hline Clean & $850(56.66)$ \\
\hline Clean contaminated & $650(43.33)$ \\
\hline \multicolumn{2}{|c|}{ Surgery Type } \\
\hline Elective surgery & $500(33.33)$ \\
\hline Emergency & $1000(66.66)$ \\
\hline \multicolumn{2}{|c|}{ Previous Surgery } \\
\hline Yes & $950(63.33)$ \\
\hline No & $550(36.66)$ \\
\hline Total & $1500(100 \%)$ \\
\hline
\end{tabular}


Shah L, Baber MSA, et al., SURGICAL SITE INFECTIONS AT TERTIARY CARE HOSPITAL

Table-IV: Association between Postoperative Infection and other Factors

\begin{tabular}{|c|c|c|c|c|}
\hline \multirow[t]{2}{*}{ Variable } & \multicolumn{2}{|c|}{ Infections } & \multirow[t]{2}{*}{ Total } & p-value \\
\hline & Yes & No & & \multirow{4}{*}{$<0.001$} \\
\hline Gender & $600(40 \%)$ & $900(60 \%)$ & $1500(100 \%)$ & \\
\hline Male & $430(28.66 \%)$ & $426(28.40 \%)$ & $856(57.06 \%)$ & \\
\hline Female & $170(11.33 \%)$ & $474(31.60 \%)$ & $644(42.93 \%)$ & \\
\hline \multicolumn{5}{|l|}{ Residence } \\
\hline Urban & $609(40.6 \%)$ & $390(.26 \%)$ & $799(53.26)$ & \multirow{2}{*}{$<0.001$} \\
\hline Rural & $191(12.7 \%)$ & $510(.34 \%)$ & $701(46.73)$ & \\
\hline \multicolumn{5}{|l|}{ Obesity } \\
\hline $\mathrm{BMI}<30 \mathrm{KG} / \mathrm{M} 2$ & $350(23.33 \%)$ & $600(40 \%)$ & $950(63.33 \%)$ & \multirow{2}{*}{0.001} \\
\hline $\mathrm{BMI} \geq 30 \mathrm{KG} / \mathrm{M} 2$ & $250(16.66 \%)$ & $300(20 \%)$ & $550(36.66 \%)$ & \\
\hline \multicolumn{5}{|l|}{ AGE in Years } \\
\hline $5-15$ & $200(13.33 \%)$ & $125(8.33 \%)$ & $325(21.66 \%)$ & \multirow{4}{*}{$<0.001$} \\
\hline $16-30$ & $179(11.93 \%)$ & $370(24.66 \%)$ & $549(36.60 \%)$ & \\
\hline $31-45$ & $173(11.53 \%)$ & $225(15 \%)$ & $398(26.53 \%)$ & \\
\hline$>45$ & $48(3.2 \%)$ & $180(12 \%)$ & $228(15.2 \%)$ & \\
\hline \multicolumn{5}{|l|}{ AS a SCORE } \\
\hline $\mathrm{I}$ & $520(34.66 \%)$ & $380(25.33 \%)$ & $900(60 \%)$ & \multirow{3}{*}{$<0.001$} \\
\hline II & $180(12 \%)$ & $270(18 \%)$ & $450(30 \%)$ & \\
\hline III & $50(3.33 \%)$ & $100(6.66 \%)$ & $150(10 \%)$ & \\
\hline \multicolumn{5}{|l|}{$\begin{array}{l}\text { Postoperative Hospital } \\
\text { Stay } \\
\end{array}$} \\
\hline$\leq 15$ DAYS & $300(20 \%)$ & $600(40 \%)$ & $900(60 \%)$ & \multirow[b]{2}{*}{$<0.001$} \\
\hline$>15$ DAYS & $300(20 \%)$ & $300(20 \%)$ & $600(40 \%)$ & \\
\hline \multicolumn{5}{|l|}{ Wound class } \\
\hline Clean & $450(30 \%)$ & $400(26.66 \%)$ & $850(56.66 \%)$ & \multirow[b]{2}{*}{$<0.001$} \\
\hline Clean contaminated & $150(10 \%)$ & $500(33.33 \%)$ & $650(43.33 \%)$ & \\
\hline \multicolumn{5}{|l|}{ Surgery type } \\
\hline Elective surgery & $100(6.66 \%)$ & $400(26.66 \%)$ & $500(33.33 \%)$ & \multirow[b]{2}{*}{$<0.001$} \\
\hline Emergency & $500(33.33 \%)$ & $500(33.33 \%)$ & $1000(66.66)$ & \\
\hline \multicolumn{5}{|l|}{ Previous surgery } \\
\hline Yes & $515(34.33 \%)$ & $435(29 \%)$ & $950(63.33 \%)$ & \multirow[t]{2}{*}{$<0.001$} \\
\hline No & $85(5.66 \%)$ & $465(31 \%)$ & $550(36.66 \%)$ & \\
\hline \multicolumn{5}{|l|}{ Diabetic } \\
\hline Yes & $350(23.33 \%)$ & $700(46.66 \%)$ & $1050(70 \%)$ & \multirow[b]{2}{*}{$<0.001$} \\
\hline No & $250(16.66 \%)$ & $200(13.33 \%)$ & $450(30 \%)$ & \\
\hline \multicolumn{5}{|l|}{ Duration of surgery } \\
\hline$>1$ hour & $300(20 \%)$ & $550(36.66 \%)$ & $850(56.66 \%)$ & \multirow[b]{2}{*}{$<0.001$} \\
\hline$\leq 1$ hour & $300(20 \%)$ & $350(23.33 \%)$ & $650(43.33 \%)$ & \\
\hline
\end{tabular}

JUMDC Vol. 12, Issue 3, July-September, 2021 


\section{DISCUSSION:}

A study conducted in 2018 in which they concluded the risk factors of surgical site infection from underweight to obesity. According to them several epidemiological studies show that body weight is related to the risk of infection as well as disease outcome. Whereas underweight in children and adolescents increases the risk of multiple infections, especially in developed countries. Both obesity and underweight have been shown to increase risk of infection in adults in a U-shaped fashion showing that normal BMI is correlated with the lower infection risk in several subjects. The current study also shows the significant result of obesity in increasing the risk of surgical site infections ${ }^{[11]}$.

A systematic review conducted on estimating prolonged stay due to health care associated infections. They concluded that long stays in hospital increased the risk of health care related infections. Our study also shows significant $p$ value i.e $<0.001$ providing evidence of higher risk of infections due to prolonged hospital stay ${ }^{[12]}$.

This current study shows the significant results that type of surgery and higher BMI are associated with SSI. Sun $Y$ et. al conducted a study in which risk factors of SSI after open reduction and internal fixation of ankle fracture were concluded. The major risk factors for SSI incidence, according to multivariate research, were open injuries, advanced age, higher BMI, chronic heart disease, and history of allergy ${ }^{[13]}$. Our study also showed more chances of infection with increase in BMI but contrary to this study more infections were seen in young patients in our study. This might be due to fact that in their study they worked on the patients of orthopedic department and in old age the healing of bones is not only slow but sometimes even there is no recovery.

A study conducted in 2019 concluded that independent risk factors for SSI during abdominal surgery are potentially modifiable, such as open surgical approach, infected wound class, and emergency surgery, should be treated routinely. This current study also considers the type of surgery as a potential risk factor for SSI [14].

Examination and identification of high risk patients is necessary to low the chances of SSI and in the same way taking appropriate measures during surgical procedure will reduce the risk of
SSI. There are different ways which can reduce the chances of SSIs like administration of first dose within one hour of surgery, Shortening the preoperative hospital stay and shortening the duration of operations. Identification of risk factors of SSI are period of preoperative stay at hospitals, time duration of surgery and ASA index [15-17]. These risk factors are identified when doing surgeries to a lot of patients and surgeries done in general $[18,19]$. Factors such as ASA index and the wound class with duration of surgeries are well identified in specific surgeries like orthopedic surgeries associated with SSIs. However, in neck and head or cardiac surgeries, these factors are not well known for the SSIs. It is important to mention the duration of surgery not only because of its effects on SSIs but also many other risks factors such as ASA index, through which it is suggesting that those patients which has large ASA index should have long duration of surgery $[20,21]$. In addition to all these, the long duration of surgery not only increase the chance of SSI but also many other complications such as wound dehiscence, development of urinary tract infection and even septic shock. The short duration of surgery can reduce the risk of SSIs. The chances of occurring SSIs in secondary and tertiary peritonitis are very high requiring ICU admission. Physicians should notice the microorganism isolated with patients having SSIs when prescribing antibiotic therapy, are more likely multi drug resistant pathogens such as Gram-positive cocci, Fungi and Pseudomonas $[22,23]$. Due to inherent limitation of sampling of microorganism with swabs done in our labs, we need more study to confirm our results. We do not find any effect in the hospital mortality in our population despite the presence of SSI associated with prolonged surgery ${ }^{[24,25]}$. In this study about 600 cases are reported of infection in which $33.3 \%$ were emergency while $6.66 \%$ were elective. The chances of occurrence of SSIs are: $4.4 \%$ in Taiwan, $7.5 \%$ in United States ${ }^{[8]}$, $5.2 \%$ in Japan ${ }^{[9]}, 6.23 \%$ in Peshawar ${ }^{[10]}$. Several factors are responsible for SSIs which varies from patient to patients, hospital environment, food, hospital staff, infected surgical instruments, dressing and even medicine and injections [26]. One of the important hosts related risk factor is advance age. Gender is not an important issue regarding SSI. 
Duration of surgery and wound class play a key role in influencing SSIs. Those procedures that have time duration of more than 2 hours are at greater risk of having SSIs. Longer hospitals stay especially in the case of post-operative period is related to increase risk of wound infectious rate.

\section{CONCLUSION:}

Surgical site infection (SSI) may occur after surgical procedure. Most common cause is not adopting proper sterilization to surgical instruments or contact from surgical team to patient skin. This may occur superficial in the skin, deep in muscle, in organ or cavity. Pus culture and sensitivity test is helpful to identify organism and sensitivity of antibiotics. Most of the patients respond well after conservative treatment but few may require alternate surgical procedure.

LIMITATIONS: The study was conducted in a single center. If same study is conducted in multiple centers than more elaborated and better results can be achieved.

\section{ACKNOWLEDGEMENT: None CONFLICT OF INTEREST: None GRANT SUPPORT \& FINANCIAL DISCLOSURE: None}

\section{REFERENCES:}

1. Campos CC, De Castro Franco LM, Rocha AD, Ercole FF. Incidência e fatores de risco para infecção de sítiocirúrgicoemcirurgias gerais1. Rev. Latino-Am. Enfermagem. 2017;25: e2848.

2. Ferreira LD, Azevedo LM, Salvador PT, Morais $\mathrm{SH}$, Paiva RD, Santos VE. Nursing care in healthcare-associated infections: a scoping review. Revista Brasileira De Enfermagem. 2019;72(2):476-483. Doi:10.1590/00347167-2018-0418

3. Ercole FF, Chianca TC, Duarte D, Starling $C E$, Carneiro M. Surgical site infection in patients submitted to orthopedic surgery: the NNIS risk index and risk prediction. Revistalatino-americana De Enfermagem. 2011;19(2):269-276.Doi:10.1590/S010411692011000200007
4. Dos Reis RG, Rodrigues MC. Post-discharge surgical site infection: occurrence and characterization of general surgery outpatients. CogitareEnferm. 2017;22(4): e51678. Doi: 10.5380/ce.v22i4.51678 ';

5. Engemann JJ, Carmeli Y, Cosgrove SE, Fowler VG, Bronstein MZ, Trivette SL, et al. Adverse clinical and economic outcomes attributable to methicillin resistance among patients with Staphylococcus aureus surgical site infection. Clinical Infectious Diseases. 2003;36(5):592608. Doi:10.1086/367653. Epub 2003 Feb 7.

6. Isik O, Kaya E, Dundar HZ, Sarkut P. Surgical site infection: re-assessment of the risk factors. Chirurgia--Romanian Journal of Surgery at the top of the best Medical Publications. 2015;110(5):457-461. Available from: http://www.revistachirurgia. ro/ pdfs/2015-5-457. https://www. researchgate.net/publication/280805136

7. Ata A, Lee J, Bestle SL, Desemone J, Stain SC. Postoperative hyperglycemia and surgical site infection in general surgery patients. Archives of Surgery. 2010;145(9):858-864. Doi:10.1001/archsurg.2010.179.

8. Curcio D, Cane A, Fernández F, Correa J. Surgical site infection in elective clean and clean-contaminated surgeries in developing countries. International Journal of Infectious Diseases. 2019; 80:34-45.Doi: 10.1016/j. ijid.2018.12.013.

9. Alkaaki A, Al-Radi OO, Khoja A, Alnawawi A, Alnawawi A, Maghrabi A, et al. Surgical site infection following abdominal surgery: a prospective cohort study. Canadian Journal of Surgery. 2019;62(2):111-117. Doi: 10.1503 /cjs.004818.

10. Levin EC, Chow C, Makhzoumi Z, Jin C, Shiboski SC, Arron ST. Association of postoperative antibiotics with surgical site infection in Mohs micrographic surgery. Dermatologic Surgery. 2019;45(1):52-57. Doi: $10.1097 / D S S .0000000000001645$

11. Dobner J, Kaser S. Body mass index and the risk of infection-from underweight to obesity. Clinical Microbiology and Infection. 2018;24(1):24-28.Doi.org/10.1016/j. cmi.2017.02.013

12. Manoukian S, Stewart S, Dancer S, Graves N, Mason $\mathrm{H}$, McFarland A, et al. Estimating excess 
length of stay due to healthcare-associated infections: a systematic review and metaanalysis of statistical methodology. Journal of Hospital Infection. 2018;100(2):222-235.

13. Sun $Y$, Wang $H$, Tang $Y$, Zhao $H$, Qin $S$, Xu L, et al. Incidence and risk factors for surgical site infection after open reduction and internal fixation of ankle fracture: A Retrospective Multicenter Study. Medicine. 2018;97(7): e9901.Doi: 10.1097/MD.0000000000009901

14. Alkaaki A, Al-Radi OO, Khoja A, Alnawawi A, Alnawawi A, Maghrabi A, et al. Surgical site infection following abdominal surgery: a prospective cohort study. Canadian Journal of Surgery. 2019;62(2):111-117.Doi: 10.1503/ cjs.004818

15. Yokoe DS, Anderson DJ, Berenholz SM. Introduction to "A compendium of Strategies to prevent healthcare associated infections in acute care hospitals- 20th updates" Infection Control Wosp Epidemiol. 2014;35(5):455459. Doi: $10.1086 / 675819$

16. Malik ZI, Nawaz T, Abdullah MT, Waqar SH, Zahid MA. Surgical Site infection in General Surgical wards at a Tertiary Care Hospital. Pakistan Journal of Medical Research. 2013; 52: 116-119.

17. Ashraf I, Mohib Y, Hasan O, Malik A, Ahmad K, Noordin S. Surgical site infection surveillance following total knee arthroplasty: Tertiary care hospital experience. Annals of Medicine and Surgery. 2018; 31:14-16. Doi: 10.1016/j. amsu.2018.04.006

18. Park J, Yoo SY, Ko JH, Lee SM, Chung YJ, Lee $\mathrm{JH}$, et al. Infection prevention measures for surgical procedures during a Middle East respiratory syndrome outbreak in a tertiary care hospital in South Korea. Scientific Reports. 2020;10(1):1-8. Doi:10.1038/ s41598-019-57216-x

19. Bhandari TR, Shahi S, Bhandari R, Poudel R. Laparoscopic cholecystectomy in the elderly: an experience at a tertiary care hospital in Western Nepal. Surgery Research and Practice. 2017. Doi10.1155/2017/8204578

20. Chaung SC, Lee KT, Chang WT, Wang SN, Kuo $\mathrm{KK}$, Chen JS, et al: Risk factors for wound infection after cholecystectomy. Journal of the Formosan Medical Association. 2004; 103 (8): 607-612. Doi: 10.1007/s00268-0174029-0
21. Cheng $H$, Chen BP, Soleas IM, Ferko NC, Cameron CG, Hinoul P. Prolonged operative duration increases risk of surgical site infections: a systematic review. Surgical Infections. 2017;18(6):722-735. Doi: 10.1089/sur.2017.089

22. Ban KA, Minei JP, Laronga C, Harbrecht BG, Jensen EH, Fry DE, et al. American College of Surgeons and Surgical Infection Society: surgical site infection guidelines, 2016 update. Journal of the American College of Surgeons. 2017;224(1):59-74. Doi: 10.1016/j.jamcollsurg.2016.10.029 PMID: 27915053

23. William GC: Risk factors for Surgical Site infections.2006; 7 Suppl 1: S7-11. DOI: 10.1089/sur.2006.7.s1-7

24. Konishi T, Harihara Y, Morikane K: Surgical Site Infection Surveillance.Nihon Geka Gakkai Zasshi. 2006; 107(5): 230-234.

25. Nisa M, Naz T, Afzal I, Hassan L, Scope of Surgical Site Infection (SSI) in Obstetrics and Gynecology. Journal of Postgraduate Medical Institute. 2005; 19(4): 438-441.

26. Allegranzi $B$, Bischoff $P$, De Jonge $S$, Zeynep $N$, Zayed B, Gomes S. Surgical Site Infections New WHO Recommendations on Preoperative Measures for Surgical Site Infection Prevention: An Evidence-Based Global Perspective. Lancet Infectious Diseases. 2016;16(12): e276-287. Doi: 10.1016/ S1473-3099(16)30398-X

\section{Author's Contribution:}

Lailama Shah: Data collection, literature research and manuscript writing.

Shahzada Amir Ahmed Baber: Help in data collection and statistical analysis.

Shabir Ahmed Lehri: Overall supervision.

Ibrahim Baloch: Collected data.

Muhammad Iqbal Khan: Statistical Analysis. Rifat Arbab: Manuscript writing and revising it critically for important intellectual content.

Submitted for Publication: 19-03-2021 Accepted After revision: 23-06-2021 